\title{
Practice Rurality of Family Physicians Enrolled in a Practice Transformation Network
}

\author{
Robert L. Phillips, Jr., MD, MSPH, Elizabeth M. Bishop, PhD, MS, \\ Lars E. Peterson, MD, PhD, and Mingliang Dai, PhD
}

The Transforming Clinical Practice Initiative prioritized the delivery of free practice transformation assistance by Practice Transformation Networks (PTNs) to small and rural practices that may otherwise lack the resources needed to succeed in Medicare's value-based payment (VBP) programs. We assessed the enrollment of rural practices in PTNs using 2016 TCPI enrollment data and American Board of Family Medicine recertification examination registration data from 2013 to 2016. PTNs enrolled a higher proportion of rural family medicine practices than are represented across the general workforce $(P<$ $.0001)$. We await more comprehensive data releases to fully understand enrollment to this important initiative. (J Am Board Fam Med 2018;31:952-956.)

Keywords: Family Medicine, Health Care Policy, Practice Transformation, Primary Care, Rural

The Centers for Medicare and Medicaid Services' (CMS) Transforming Clinical Practice Initiative (TCPI) is one of the largest federal investments to date designed to "support clinician practices through nationwide, collaborative, and peer-based learning networks that facilitate large-scale practice

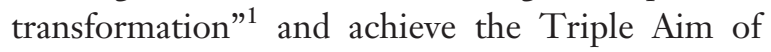
improving the health of the population, improving patient experience, and reducing costs. ${ }^{2}$ When launched in September 2015, the TCPI aimed to rapidly enroll 140,000 clinicians into 1 of 29 Practice Transformation Networks (PTNs). The PTNs - created by existing entities with practice transformation and quality improvement expertise,

This article was externally peer reviewed.

Submitted 7 August 2017; revised 31 March 2018; accepted 9 April 2018.

From the American Board of Family Medicine, Lexington, $\mathrm{KY}$.

Funding: The project described was supported by Funding Opportunity CMS-1L1-15-002 from the U.S. Department of Health \& Human Services, Centers for Medicare \& Medicaid Services. The contents provided are solely the responsibility of the authors and do not necessarily represent the official views of HHS or any of its agencies. The American Board of Family Medicine, Inc. owns and operates the PRIME Registry.

Conflict of interest: none declared.

Corresponding author: Robert L. Phillips, Jr., MD, MSPH, Vice President for Research and Policy, The American Board of Family Medicine, 1648 McGrathiana Pkwy, Suite 550, Lexington, KY 40511 (E-mail: bphillips@theabfm.org). for example, the Consortium for Southeastern Hypertension Control and the Pacific Business Group on Health-were funded to provide clinicians and their practices with free coaching and tools to help transition to (VBP) programs, specifically, Medicare's Merit-Based Incentive Payment System and Advanced Alternative Payment Programs, for example, Comprehensive Primary Care Plus or the Medicare Shared Savings Program. The 29 PTNs covered all 50 states, but some more remotely than others. Total PTN enrollment numbers have not been released to date, but most networks reported being near full enrollment capacity by the end of 2016 .

The TCPI also awarded 10 cooperative agreements to medical specialty societies and other organizations with large clinician constituents, like the American Board of Family Medicine (ABFM), to create Support and Alignment Networks (SANs) to disseminate TCPI best practices and to provide additional transformation support to PTN enrolled clinicians. The ABFM created the PRIME SAN to achieve our shared goals to: support PTNs practice transformation work and reduce the burden of family medicine certification using our PRIME Registry data tools; to provide continuous certification in recognition of the work of transformation and related quality improvement; and, to support family physicians working in "small practices, practices located in rural areas, and practices caring for med- 
ically underserved populations." ${ }^{1}$ Previous research provides considerable evidence that small and rural primary care practices deliver high-value care, but they lack the resources to transform their practices including the ability to collect and manage the clinical quality measure data required by VBPs. ${ }^{3-6}$ The PRIME SAN aimed to solve both of these problems by recruiting family physicians in small and rural practices to enroll in PTNs and by offering those practices 3 years of free enrollment in the PRIME Registry, our quality improvement and reporting tool, which is a CMS-certified Qualified Clinical Data Registry, open to all primary care clinicians. ${ }^{7}$ In this initial investigation, our primary objective was to assess the enrollment of small and rural practices in the TCPI by testing the hypothesis that there are a greater proportion of rural practices enrolled in PTNs than are found among nonenrolled practices. We also assessed variation in enrollment of family physicians (FPs) across states and PTNs.

\section{Methods}

Complete PTN enrollment data have not been released by TCPI, including practice addresses, making our analysis more difficult. We obtained practice size and rurality for PTN enrolled FPs through an alternate method, which also allowed us to readily create a comparison cohort of nonenrolled FPs. We did so by matching the National Provider Identifier and first and last name for 7651 PTN-enrolled FPs provided to the PRIME SAN by the TCPI data support contractor through December 2016, with the National Provider Identifiers of FPs completing a demographic questionnaire as they registered for the 2013 to 2016 ABFM Family Medicine recertification examination. This match identified our cohort of 2,886 PTN enrollees and a comparison cohort of 34,279 non-PTN FPs.

To determine rurality, we used the practice zip code self-reported in the recertification examination registration questionnaire to approximate $\mathrm{Ru}-$ ral Urban Commuting Area (RUCA, version 2.0) codes, which were then collapsed into 4 categories: urban, large rural, small rural, and isolated. ${ }^{8} \mathrm{We}$ created contingency tables and performed $\chi^{2}$ tests to determine whether the observed difference in percentages of PTN enrolled and non-PTN enrolled FPs across practice rurality was statistically significant.
Table 1. Practice Rurality of Family Physicians Enrolled in a Practice Transformation Network (PTN)

\begin{tabular}{lccc}
\hline & & & $\chi^{2}$ \\
\hline Sample size & 2886 & Non-PTN & $P$ Value \\
Rurality (\%) & & & \\
Urban & $2080(72 \%)$ & $26,865(78 \%)$ & $<.0001$ \\
Large rural & $351(12 \%)$ & $3642(11 \%)$ & .01 \\
Small rural & $280(10 \%)$ & $2285(7 \%)$ & $<.0001$ \\
Isolated & $138(5 \%)$ & $1085(3 \%)$ & $<.0001$ \\
Unclassified* & $37(1 \%)$ & $402(1 \%)$ & .60 \\
\hline
\end{tabular}

The sample of this analysis included 37,165 family physicians, 2886 in PTNs and 34,279 not in PTNs, who registered for an ABFM recertification exam between 2013 and 2016.

*One percent of the zip codes did not match to RUCA.

\section{Results}

We matched 2,886 of the 34,279 ABFM examinees from 2013 to 2016 to the 7651 PTN enrolled FPs. Compared with non-PTN FPs ( $\mathrm{n}=$ 34,279) registering for the ABFM examination from 2013 to 2016, FP recertification examination registrants enrolled in PTNs $(\mathrm{n}=2,886)$ were more likely to be in rural practice (Table 1; $P<.0001)$.

As of the end of 2016, 7,237 (of 7,651) PTNenrolled FPs were ABFM certified. Concurrently, the total number of ABFM Diplomates was 87,939 , which yielded a national PTN enrollment rate of $8.2 \%$ among Board ABFM-certified FPs (Table 2). Less than $1 \%$ of ABFM Diplomates in Vermont, Nevada, District of Columbia, and Wyoming were enrolled, but more than 1 in 4 FP Diplomates in South Dakota and North Dakota were enrolled (Table 2). Ten percent or more of ABFM Diplomates in 17 states were enrolled, but enrollment variation was quite large (Table 2).

Just as there was variation across states, there was similar variation across PTNs in their enrollment of FPs. For example, the Compass/Iowa Health care Collaborative PTN enrolled clinicians far beyond Iowa and had a clear mission of enrolling rural practices. Thus, Compass enrolled nearly 1 in 7 of all PTN-enrolled FPs. Four other PTNs have more than 500 FPs (in order): Great Lakes/ Indiana University, National Rural Accountable Care Consortium, Vizient, and Pacific Business Group on Health/California Quality Collaborative (data not shown). 
Table 2. Practice Transformation Network (PTN) Enrollment of Board-Certified Family Physicians by State, 2016

\begin{tabular}{|c|c|c|c|}
\hline State & $\begin{array}{l}\text { Total Number of } \\
\text { Board-Certified FPs }\end{array}$ & $\begin{array}{c}\text { Total Number of Board-Certified } \\
\text { FPs in PTN }\end{array}$ & $\begin{array}{l}\text { Percentage of Board-Certified FPs } \\
\text { in PTN (in Ascending Order) }\end{array}$ \\
\hline National & 87,939 & 7237 & $8.2 \%$ \\
\hline Vermont & 298 & 1 & $0.3 \%$ \\
\hline Nevada & 547 & 3 & $0.5 \%$ \\
\hline District of Columbia & 147 & 1 & $0.7 \%$ \\
\hline Wyoming & 232 & 2 & $0.9 \%$ \\
\hline Massachusetts & 1437 & 28 & $1.9 \%$ \\
\hline Maryland & 1302 & 34 & $2.6 \%$ \\
\hline Pennsylvania & 3764 & 100 & $2.7 \%$ \\
\hline Oregon & 1647 & 44 & $2.7 \%$ \\
\hline Texas & 6664 & 192 & $2.9 \%$ \\
\hline Colorado & 2212 & 67 & $3.0 \%$ \\
\hline Maine & 700 & 25 & $3.6 \%$ \\
\hline Delaware & 248 & 9 & $3.6 \%$ \\
\hline Florida & 4383 & 178 & $4.1 \%$ \\
\hline Montana & 481 & 22 & $4.6 \%$ \\
\hline Arkansas & 878 & 46 & $5.2 \%$ \\
\hline Utah & 919 & 49 & $5.3 \%$ \\
\hline Missouri & 1497 & 83 & $5.5 \%$ \\
\hline New Jersey & 1333 & 74 & $5.6 \%$ \\
\hline Illinois & 3630 & 204 & $5.6 \%$ \\
\hline Michigan & 2677 & 151 & $5.6 \%$ \\
\hline Oklahoma & 935 & 54 & $5.8 \%$ \\
\hline Ohio & 3078 & 185 & $6.0 \%$ \\
\hline Hawaii & 427 & 28 & $6.6 \%$ \\
\hline Alaska & 405 & 27 & $6.7 \%$ \\
\hline South Carolina & 1471 & 104 & $7.1 \%$ \\
\hline West Virginia & 618 & 48 & $7.8 \%$ \\
\hline Arizona & 1551 & 124 & $8.0 \%$ \\
\hline Tennessee & 1651 & 140 & $8.5 \%$ \\
\hline Wisconsin & 2392 & 205 & $8.6 \%$ \\
\hline Louisiana & 979 & 84 & $8.6 \%$ \\
\hline Connecticut & 557 & 51 & $9.2 \%$ \\
\hline Georgia & 2233 & 208 & $9.3 \%$ \\
\hline Alabama & 1083 & 104 & $9.6 \%$ \\
\hline California & 10,194 & 981 & $9.6 \%$ \\
\hline Kentucky & 1068 & 109 & $10.2 \%$ \\
\hline North Carolina & 3100 & 318 & $10.3 \%$ \\
\hline New York & 3396 & 350 & $10.3 \%$ \\
\hline Iowa & 1389 & 144 & $10.4 \%$ \\
\hline Rhode Island & 231 & 27 & $11.7 \%$ \\
\hline Minnesota & 2868 & 366 & $12.8 \%$ \\
\hline Washington & 3278 & 420 & $12.8 \%$ \\
\hline Idaho & 653 & 90 & $13.8 \%$ \\
\hline Virginia & 2726 & 410 & $15.0 \%$ \\
\hline New Mexico & 703 & 116 & $16.5 \%$ \\
\hline Indiana & 2142 & 395 & $18.4 \%$ \\
\hline Mississippi & 540 & 100 & $18.5 \%$ \\
\hline New Hampshire & 517 & 98 & $19.0 \%$ \\
\hline Kansas & 1187 & 235 & $19.8 \%$ \\
\hline Nebraska & 798 & 197 & $24.7 \%$ \\
\hline South Dakota & 390 & 110 & $28.2 \%$ \\
\hline North Dakota & 328 & 96 & $29.3 \%$ \\
\hline
\end{tabular}




\section{Discussion}

This analysis is a first investigation into the penetration of TCPI technical assistance to family physicians. Our analysis of recertifying FPs enrolled in PTNs suggests that TCPI succeeded in enrolling a greater proportion of rural FP practices than the general FP workforce. While we have no reason to believe that this group of recertifying FPs systematically differs from the larger group of all boardcertified FPs or nonboard-certified FPs, with regard to rurality, we anticipate verifying this in the future. The considerable variation in state enrollment of family physicians is due to a combination of things. One reason for variation is likely due to differences in focus of each PTN. Some PTNs were based in closed health systems, such as Mayo Clinic, which drew their main enrollment from their system rather than the broader, target geography. Another reason is that the recruitment timeline was shortened from its original plan, leading some PTNs to change their strategy to capturing large groups of physicians, often hospitals or health systems, which are to have rural and small practices. The third likely reason for the enrollment variation is competition from other demonstrations projects or related, disqualifying practice affiliations. For example, several states participated in the Comprehensive Primary Care Plus $(\mathrm{CPC}+)$ payment demonstration, and many practices were already in shared-savings Accountable Care Organizations. The recruitment variation suggest that many small and rural primary care practices would still benefit from assistance in succeeding under the Quality Payment Program. Only 4 of 14 (whole-state) CPC + states had TCPI enrollments at or above the national average, suggesting that practices may be more likely to choose payment over facilitation to support change. Policy options that come from these demonstrations will need to consider how they will reach most small practices, and whether and how to blend payment and facilitation to support transformation.

We had also desired to assess enrollment of smaller practices since they deliver high-quality care but often lack access to resources to transform and meet new reporting requirements. ${ }^{3-5}$ However, there is considerable evidence of family medicine practice relocation within the 3 years analyzed that, without primary data from PTNs, ABFM recertification data were not sufficiently reliable to perform this analysis. Despite differences in most recent practice address and practice address at recertification, rural location remained $85 \%$ concordant between the 2 addresses for rural, and 98\% concordant for urban. The other main limitation to this initial analysis of PTN-enrolled FPs was that we could not analyze the full sample of 7237 who are ABFM-certified because TCPI did not release address data collected by PTNs, limiting us to the 2886 we could analyze. In response to this limitation we compared this cohort to their peers (also recertified between 2013 and 2016), reducing the likelihood of systematic bias. The other minor limitation was that 414 or $5.4 \%$ of our matched sample of enrolled FPs are not currently certified by the ABFM.

Future studies will re-examine final enrollment and practice characteristics if CMS will make these data available. Future studies will also address our second aim, understanding whether enrollment in the PRIME Registry, our quality improvement and reporting tool, supported assessment of quality and cost improvement. Our ongoing goals are to improve understanding of which practice features and transformation support are associated with measurable improvement and success in value-based payment programs.

To see this article online, please go to: http://jabfm.org/content/ 31/6/952.full.

\section{References}

1. Center for Medicare \& Medicaid Services. Transforming clinical practice initiative. 2016. Available from: https://innovation.cms.gov/initiatives/TransformingClinical-Practices/.

2. Berwick DM, Nolan TW, Whittington J. The Triple Aim: Care, health, and cost. Health Affairs 2008; 27:759-69.

3. Casalino LP, Pesko MF, Ryan AM, et al. Small primary care physician practices have low rates of preventable hospital admissions. Health Affairs 2014; 33:1680-8.

4. Bazemore A, Petterson S, Peterson LE, Phillips RL. More comprehensive care among family physicians is associated with lower costs and fewer hospitalizations. Ann Fam Med 2015;13:206-13.

5. Phillips RL Jr, Kaufman A, Mold JW, et al. The primary care extension program: A catalyst for change. Ann Fam Med 2013;11:173-8.

6. Mafi JN, Wee CC, Davis RB, Landon BE. Association of primary care practice location and ownership with the provision of low-value care in the 
United States. JAMA Internal Medicine 2017;177: $838-45$.

7. The American Board of Family Medicine PRIME Registry. 2017. Available from: http://primenavigator.org/primeregistry/. Accessed July 9, 2017.
8. WWAMI Rural Health Research Center. RUCA Data: Travel distance and time, remote, isolated, and frontier. 2013. Available from: http://depts.washington.edu/uwruca/ruca-travel-dist.php. Accessed June $12,2015$. 